\title{
DISPLACEMENT MEASUREMENT OF ADJACENT SUPER HIGH-RISE BUILDINGS USING GPS
}

\section{GPS を用いた隣接した超高層 建物の変位測定}

\author{
Ali NIOUSHA — $* 1 \quad$ Michio IMAI — $* 2$ \\ Keywords : \\ RTK-GPS, Real-time monitoring, Super-high-rise building, Displacement \\ measurement \\ キーワード : \\ RTK-GPS，リアルタイムモニタリング，超高層建物，変位測定
}

ニウシャアリ—*1 今井道男 — $* 2$

It is shown that the RTK-GPS can be used for monitoring the displacement response of high-rise buildings in real-time. First, the applicability of the system is checked using test specimen, which can simulate high-rise buildings. Then, the system is simultaneously applied to two super-high-rise buildings during a windy day. It is concluded that although the dynamic response of the towers is not well tracked because of low amplitude of dynamic vibration, the long period displacement is observed. Such information can be used to track the behavior of the adjacent high-rise buildings for external loads.

\section{Introduction}

The objective of the study reported here is to investigate the applicability of the GPS technology to monitor the displacement response of the adjacent high-rise buildings for external loads. The main advantage of this technique compared to other measurements is that we can measure the building displacement directly in a real-time. Relative displacement to the ground is needed to discuss drift and stress condition of the structure, which are difficult to measure directly ${ }^{1)}$. Till now the accelerometer are used for dynamic observation of the structure, and a double integration is required to calculate the displacement. This process leads to error when there is a static or permanent displacement (such the case of strong wind, or damage due to strong shaking). The accelerometer measurement cannot recover this displacement in centimeter level. Furthermore, due to the sensor characteristics, very low frequencies cannot be accurately observed in order to track very long period or the static displacement. In addition to the accelerometer measurements, the laser displacement sensors can be used to directly measure the displacement of the buildings. But its use is limited to the indoor experiments. To solve this problem, GPS technology can be used instead. The GPS is originally a system to find the locations and directions using satellites as a reference points. By this system a three-dimensional location as well as time and velocity can be measured with high accuracy ${ }^{2}$.

It is shown in this report that the Real Time Kinematics (RTK) GPS can be used for monitoring the displacement response of high-rise buildings in real-time. First, the applicability of the system is checked using test specimen, which can simulate high-rise buildings. Then, the system is simultaneously applied to two adjacent high-rise buildings (Seiroka, St. Luke, twin towers, Tokyo), during a windy day. To the authors knowledge, this is the first simultaneously use of GPS units for displacement measurement of

\footnotetext{
*1 Senior Research Engineer, Kajima Corp., Kajima Technical Research Institute, Dr. Eng.

*2 Research Engineer, Kajima Corp., Kajima Technical Research Institute
}

adjacent high-rise buildings in Japan.

In the following sections, a brief description of the GPS system, the cause of the errors in the observations, the use of the system on a model test, the actual deployment of GPS to high-rise buildings and at the end the concluding remarks are discussed.

\section{General description of GPS}

The NAVSTAR Global Positioning System (GPS) is a satellite-based positioning and time-transfer system, designed and operated by U.S. Department of Defense. GPS is an all-weather, available 24 hours a day, which can directly observe the displacement in three-dimensional direction ${ }^{3)}$. The system consists of three main segments:

1- The Space Segments: The space segments are the satellites (24 satellites) and their orbits (six orbital planes). Each satellite is equipped by a precise atomic clock, and transmits especial signals to the earth.

2- The Control Segments: The satellites are not fixed and move on the space. Five stations around the world monitor the orbit and the exact time as well as the health condition of the satellites. The predicted orbit and exact time of each satellite are calculated and relayed to them, by these control segments. The control segments are equipped by 10 atomic clocks (each) that can calculate very precise time.

3- The User Segments: any user on the ground can be the user segment. Actually this user has an antenna and receiver to get the transmitted signals from the satellites.

GPS receivers calculate the time that is needed to a signal traveling from the satellites to the user antenna. This time multiplied by the speed of the light $(300000 \mathrm{~km} / \mathrm{s})$ gives the distance. The signals from satellite are in two patterns: Carrier (granularity of

\footnotetext{
*1 (怢鹿島建設技術研究所 主任研究員 ·博士 (工学)

(率182-0036 調布市飛田給2-19-1)

*2 侏鹿島建設技術研究所 研究員
} 


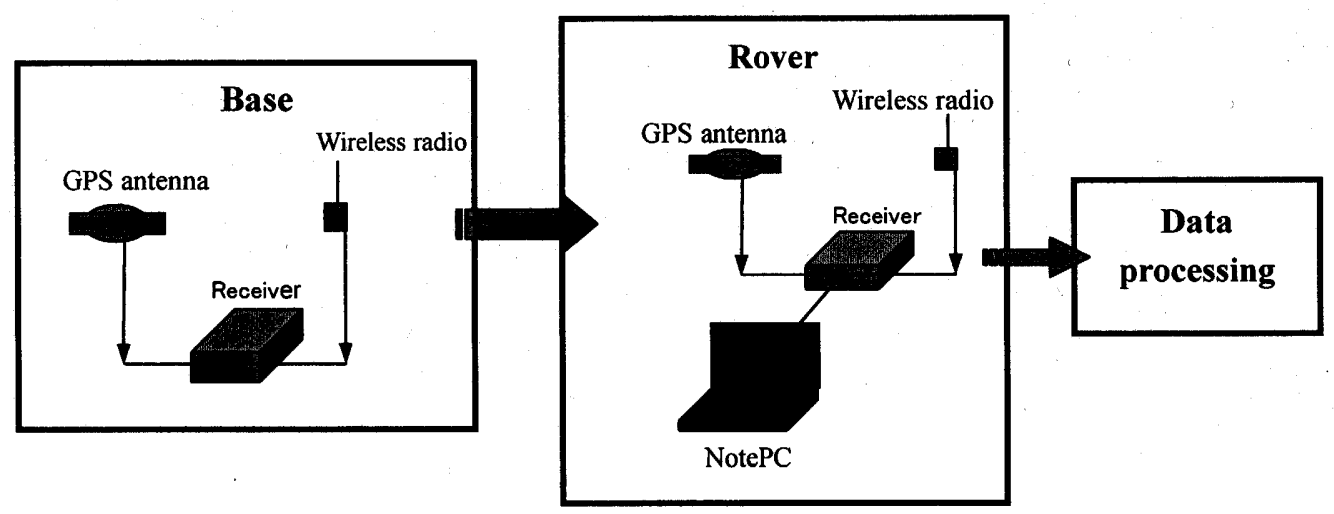

Fig.1 Layout of the RTK-GPS system.

$1 \mathrm{~mm}$ and length of $20 \mathrm{~cm}$ ) and Code (granularity of $1 \mathrm{~m}$ and unlimited length). Having these two patterns, theoretically one can measure the distance in mm accuracy but due to some errors the accuracy of the measurements are in order of several meters (about 20m).

The main sources of errors are as follows:

Satellite atomic clock error: 1 billionth of second every 3 hours, which cause $30 \mathrm{~cm}$ error in measurements. Control segments use 10 atomic clocks to correct this error.

Receiver clock error: the receiver clock must be cheap, this cause a large error in the measurement. With 3 satellites, actually the three coordinate positions can be obtained. Since the receiver clock is not precise another unknown parameter enters to the equations. To solve the problem we can use 4 satellites information instead of 3 .

Satellite orbit error: To calculate our position we must know the exact location of the reference (satellite). Due to interaction force between the earth and the satellite and other exciting force, the satellite orbit is not exactly known. The control segment is responsible to monitor and predict the orbit of the satellites for the next 24 hours. This information is relayed to the satellite and sent to receivers with the message part of the signals. This few meters of error can be also removed from the system.

Atmospheric error: Ionosphere and troposphere are the main reason of this error. The speed of the light varies due to atmospheric conditions. The impact of the ionosphere on electronic signals depends on the frequency of the signal. So if the signal patterns are transmitted via two different frequencies from the satellites, knowing the difference between the two signals, it is possible to remove the ionosphere error. Using a dual frequency receiver (L1/L2), which is more expensive than the single frequency receiver (L1), the ionosphere error can be removed. The only way to remove the troposphere error is the use of mathematical model.

Multipath: The signals from the satellite must directly reach to the user segment. If these signals are reflected from solid body, it causes the multipath error. To remove the error, signal processing technique or multipath rejection choke rings can be used.

Geometric Dilution Of Precision (GDOP): The arrangement of the satellites on the space is another factor in the errors of measurements. If the satellites are near each other the error is high but if they are scattered the measured position will have less error.

The above errors generate an error of $20 \mathrm{~m}$ in the estimation of the position. To solve this problem, the differential mode can be used.
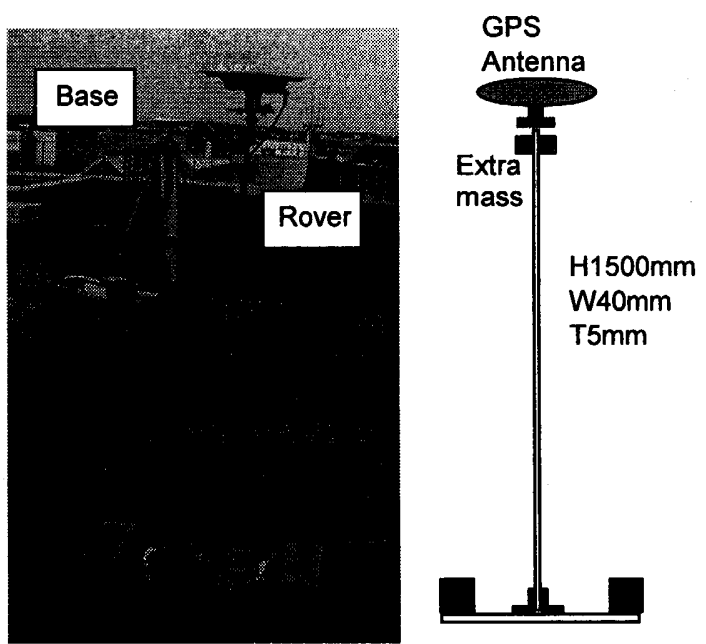

Fig.2 Model test (rover) and base station.

Having two receivers not too far from each other's, the errors describe above will be the same in both receivers, and knowing the exact location of one of the base, the errors can be mostly removed in the Rover. This is the concept of RTK-GPS. The RTK-GPS uses the carrier pattern to calculate the distance of the satellite and the receiver. In this mode, since we deal with other unknown, another satellite is needed (total of 5 satellites). Once the initial unknown integer is determined (number of full cycles that must be added to or subtracted from the distance of the satellite), then 4 satellites are enough for the system.

A general layout of RTK-GPS measurement is shown in Fig.1.

\section{Model test}

To confirm the applicability of the GPS technology to observe the displacement response of the buildings, an experimental model test has been performed using RTK-GPS. The receivers are Topcon GP-DX1 type with frequency sampling of $5 \mathrm{~Hz}$. This receiver is a dual frequency receiver $(\mathrm{L} 1 / \mathrm{L} 2)$. The margin of error specified by the manufacturer using RTK-mode is $\pm 10 \mathrm{~mm}$ in horizontal direction.

The investigated model (rover) has been made using a $1500 \mathrm{~mm}$ height steel bar with wide of $40 \mathrm{~mm}$ and thickness of $5 \mathrm{~mm}$ (Fig.2). The antenna is fixed at the top of the steel bar, which is fixed to a stiff and heavy base at the other side. The expected vibration 

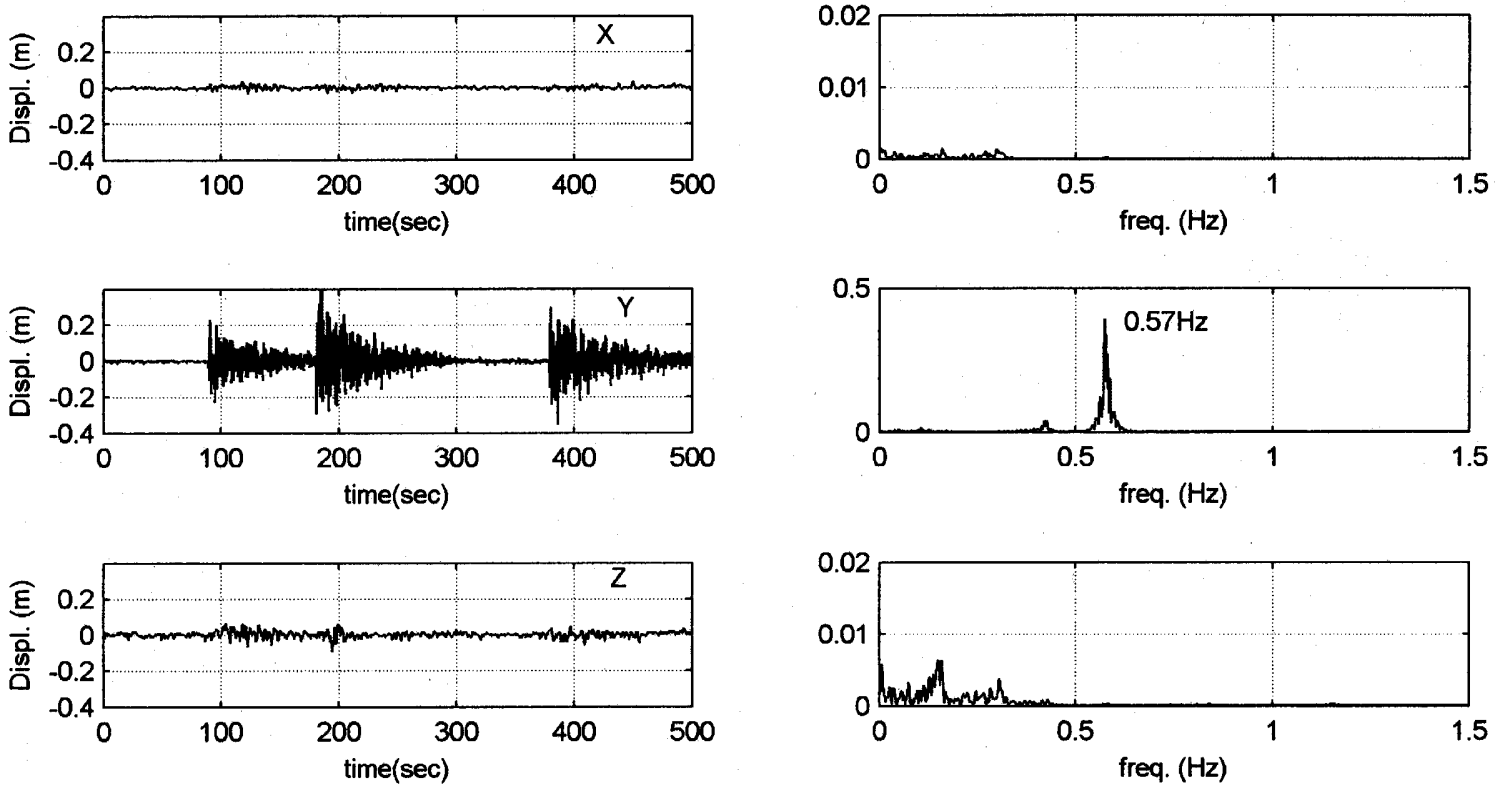

Fig.3 Displacement waveforms and power spectra in Run-1.
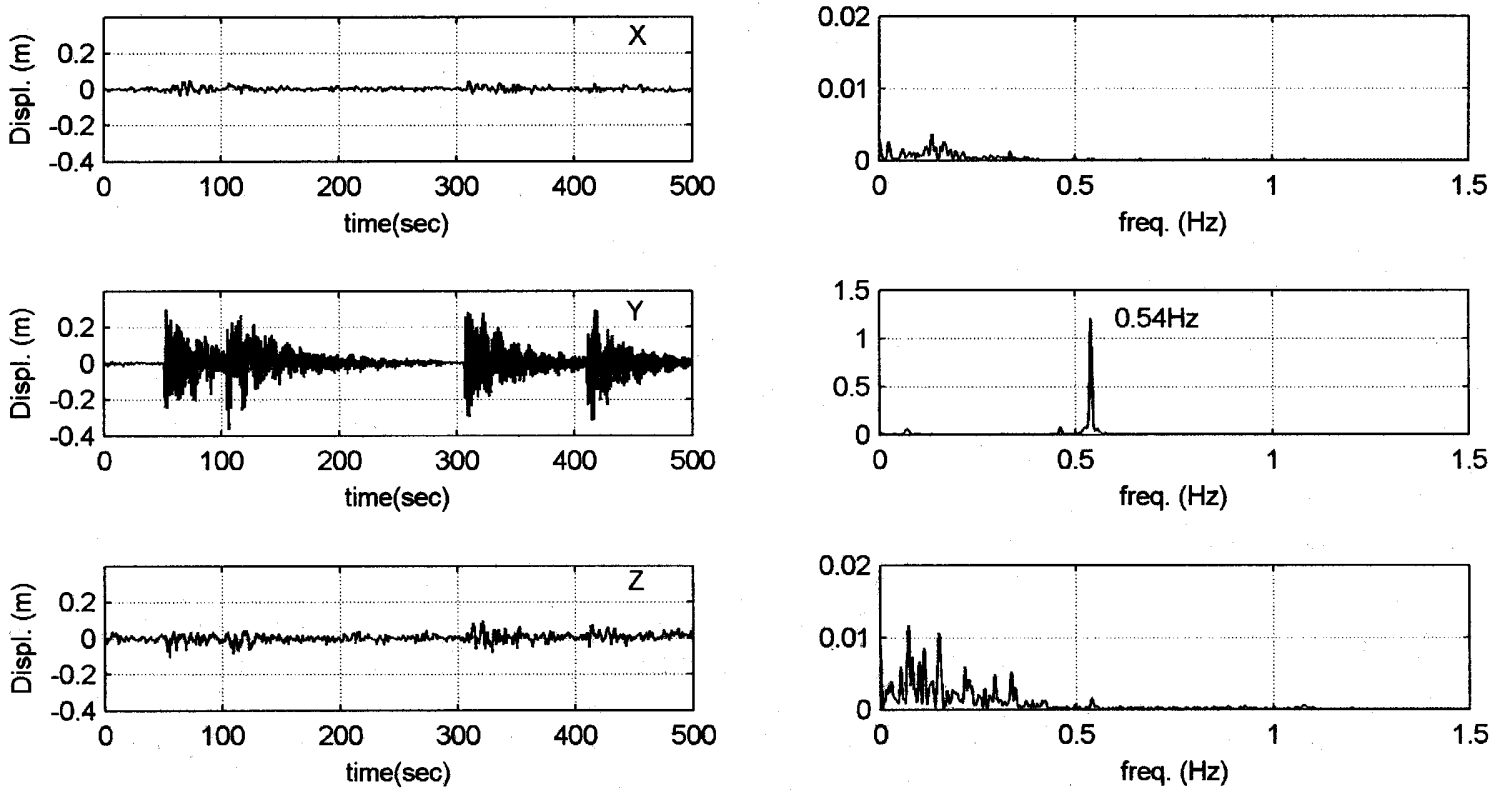

Fig.4 Displacement waveforms and power spectra in Run-2.
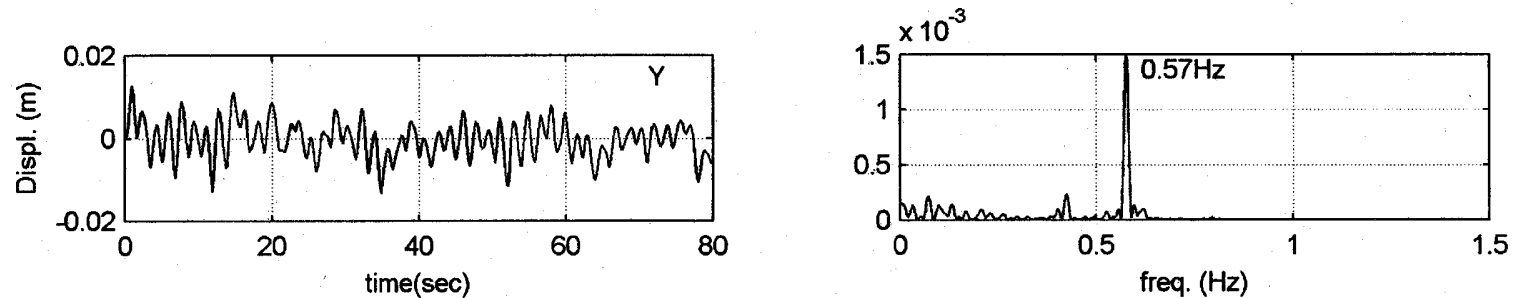

Fig.5 Y-direction displacement waveform $(\mathrm{t}=0 \sim 80 \mathrm{sec})$ and power spectra in Run-1.

frequency of the model is around $0.5-0.6 \mathrm{~Hz}$, which can model a high-rise building of about 20 floors $(T \approx 0.1 \mathrm{~N})$. To investigate the change of dynamic characteristics of the model, two different cases are investigated. Run-1 is the case without any extra-mass in the 

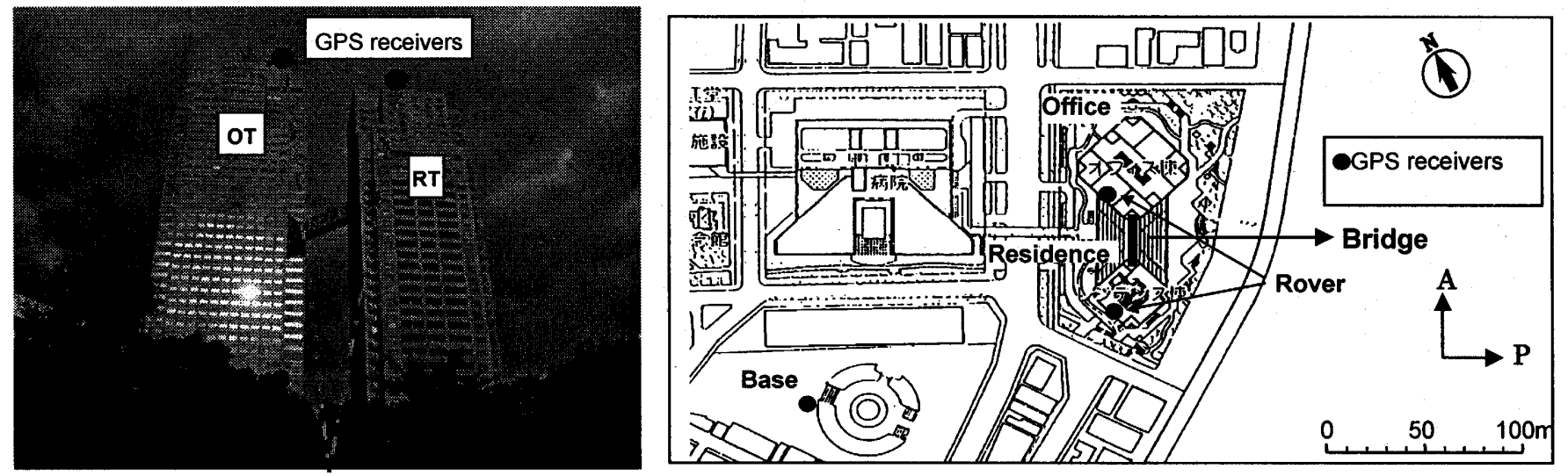

Fig.6 Layout of the investigated buildings and GPS system installation.

model and Run- 2 is the case with 300 grs extra mass. By providing an initial displacement, the bar is set to free vibration and data are recorded. The actual data are in global NS and EW directions and by transforming the components to $\mathrm{XY}$ coordinates ( $\mathrm{Y}$ is the direction of the vibration), the displacement waveforms are obtained for each run.

Run-1 was 2500 pts and Run- 2 was 2900 pts (sampling 5 pts $/ \mathrm{sec}$ ), and using an 8192pts FFT, the power spectrum of each motion is calculated. Figs. 3 and Fig. 4 show the displacement waveforms and corresponding power spectra. The fundamental frequency in Y-direction for Run-1 is $0.57 \mathrm{~Hz}$ and for Run-2 is $0.54 \mathrm{~Hz}$. The Xdirection has not clear peak and the wave in this direction can be considered as noise. To show the accuracy of the method and have an idea about the noise level, the first $80 \mathrm{sec}$ of the Run-1 is taken (before the initial displacement was applied) and the waveform and power spectrum in Y-direction are plotted (Figs.5). It can be seen that even in such a small displacement $(1 \mathrm{~cm})$, the peak at $0.57 \mathrm{~Hz}$ can be obtained in Y-direction.

\section{Actual deployment of GPS to high-rise buildings}

\subsection{Buildings and system descriptions}

The actual deployment of the GPS monitoring is carried out on Seiroka, St. Luke, twin towers. The buildings are a 51-story Office Tower (OT) and a 38-story Residence Tower (RT), which are connected with an elevated bridge at $32^{\text {nd }}$ floor of RT and $28^{\text {th }}$ floor of OT. Each side of the bridge has a pin or roller mechanism. The buildings dynamic characteristics estimated from microtremor observations are reported by Naito ${ }^{4}$. The fundamental frequency of the OT is $0.27 \sim 0.29 \mathrm{~Hz}$ and $0.41 \mathrm{~Hz}$ for the RT.

The GPS system is composed of two subsystems:

1- One base station comprising a GPS antenna, receiver, short-range wireless communication system to links the base station to rovers and battery backup to operate without power supply, located at the ground of a public park in front of the buildings.

2- Two rover stations located at the roof-floor of each tower. Each rover comprising a GPS antenna, receiver, short-range wireless communication system to links to the base station, a battery backup to operate without power supply, and a PC for data acquisition.

Fig. 6 shows the layout of the installation of GPS units. The observed records are in global N-S coordinate and the A-P
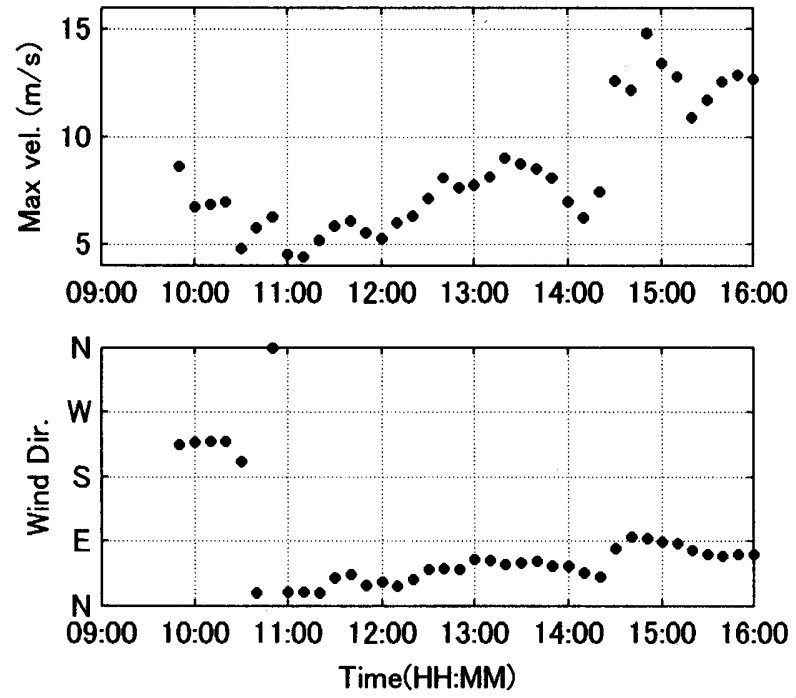

Fig.7 Maximum wind velocity and direction observed at top-floor of OT.

coordinate is also introduced which $\mathrm{A}$-axis is along and $\mathrm{P}$-axis is perpendicular to the connecting bridge.

\subsection{Data measurement and analysis}

The monitoring starts at 10:00AM and continues till 15:45PM of the same day. The observation faces some difficulties in the starting stage, especially the communication between the base station and the two rovers. In addition, in order to have an accurate observation, the observed satellites in rover and base must be identical (four satellites), which sometimes were violated. The reason can be due to the obstacle made by surrounding buildings. This information can be tracked in the transmitted data from the receiver to the PC.

The wind direction and maximum velocity during the observation are also recorded using the anemometer located at top of OT. The information is obtained from the average of every ten minutes records. Fig. 7 shows this information. It can be seen that the maximum wind velocity is around $15 \mathrm{~m} / \mathrm{s}$ and the wind blows mostly from east.

Considering the displacement waveforms in both towers, the waveforms from 15:20 to 15:45 (25 minutes) are well recorded in both towers and the wind velocity is relatively strong in this period 

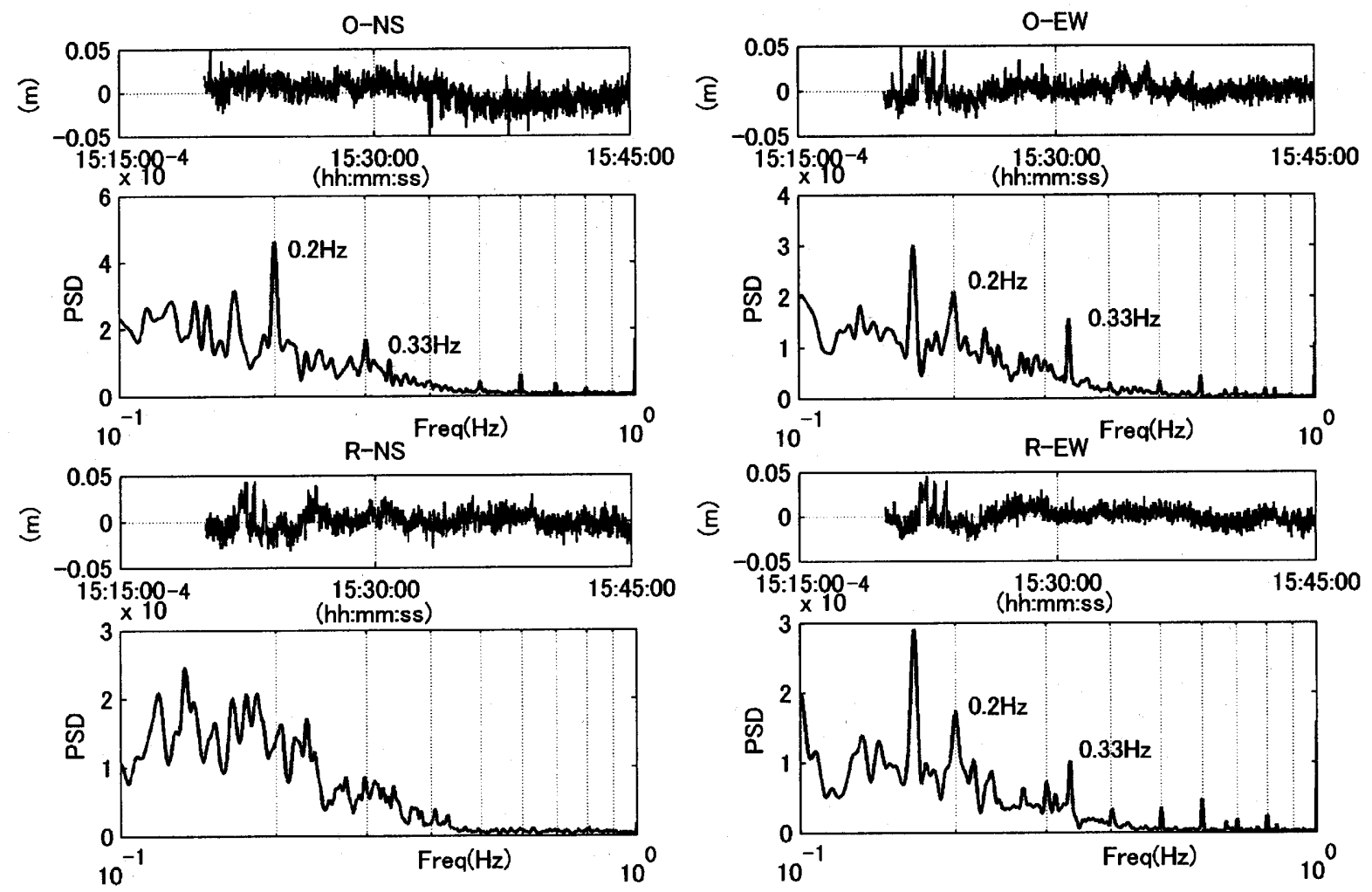

Fig.8 Displacement waveforms and corresponding power spectra in OT and RT using GPS.

of time (maximum wind velocities are $11 \mathrm{~m} / \mathrm{s}$ to $13 \mathrm{~m} / \mathrm{s}$ ). Fig. 8 show the displacement waveforms and corresponding smoothed power spectra in NS and EW direction at both towers. It must be noted that the displacement waveforms are plotted by removing the average of the records from the waves. Since the dynamic response of both towers around their fundamental frequencies were less than $10 \mathrm{~mm}$ of the RTK-GPS accuracy, therefore such information is not well tracked during the observation. These degrees of vibration are also checked using velocity meter installed at the same level of the GPS receiver. However, the $0.2 \mathrm{~Hz}$ peak in OT and $0.33 \mathrm{~Hz}$ in $\mathrm{RT}$, which are around the fundamental frequencies of each tower, respectively, are observed in the power spectra. The presence of same vibration frequency in both towers suggests that the two towers interact during the vibration. Though the vibration characteristics of the towers are not accurately observed, long period movements due to the wind load are well recorded. The power spectra of long period motion of the towers are plotted in Fig.9. Since the number of data in lower frequency is very few, therefore the smoothing is not applied to the power spectra. It can be seen that the motion in both towers has their most power in period longer than $100 \mathrm{sec}$ (less than $0.01 \mathrm{~Hz}$ ). In the following part the discussion will be concentrated on long period displacement of both towers due to the wind load. It must be noted that the accuracy of the dynamic response of the both towers must be examined further for larger vibration level in the future investigations.

In order to have a precise look to the movement of the towers, the first 5 minutes of the recorded data are investigated. The orbits of the displacement waveforms between 15:20 to 15:25, in NS and EW direction, recorded in both towers are plotted in Fig.10. The time history of the records as well as the wind direction is also plotted in the same figure. The followings can be stated:

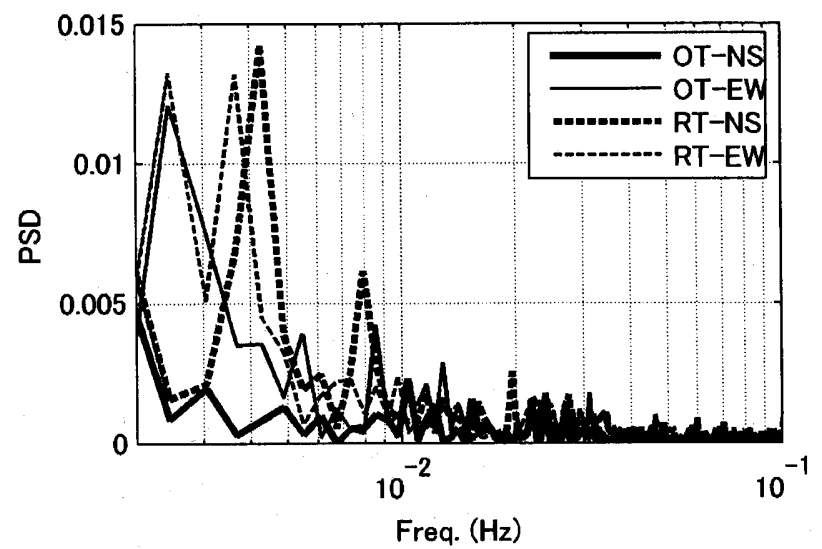

Fig.9 Long period power spectra at OT and RT.

i) The wind direction and the orbit of the horizontal displacement waveforms in OT are consistent with each other.

ii) The time histories of the EW components in both towers are in-phase in most portion of the observation.

iii) The RT moves close to the bridge direction instead the wind direction. By considering the towers arrangement and the wind direction, the effect of shielding may cause change in the flow pattern and direction around RT.

iv) The reason why the RT moves close to the A-axis can be also due to the presence of the connection bridge.

v) A sudden shift in buildings deflection at 15:22.00 to 15:22:27, $15: 22: 43$ to $15: 22: 55$ and $15: 23: 23$ to $15: 23: 35$ may be due to sudden change of gust of wind or change of wind direction. It is known that such sudden changes may be causing the flow alternately separating and attaching to the buildings).

vi) Such information can be used to track the behavior of the 

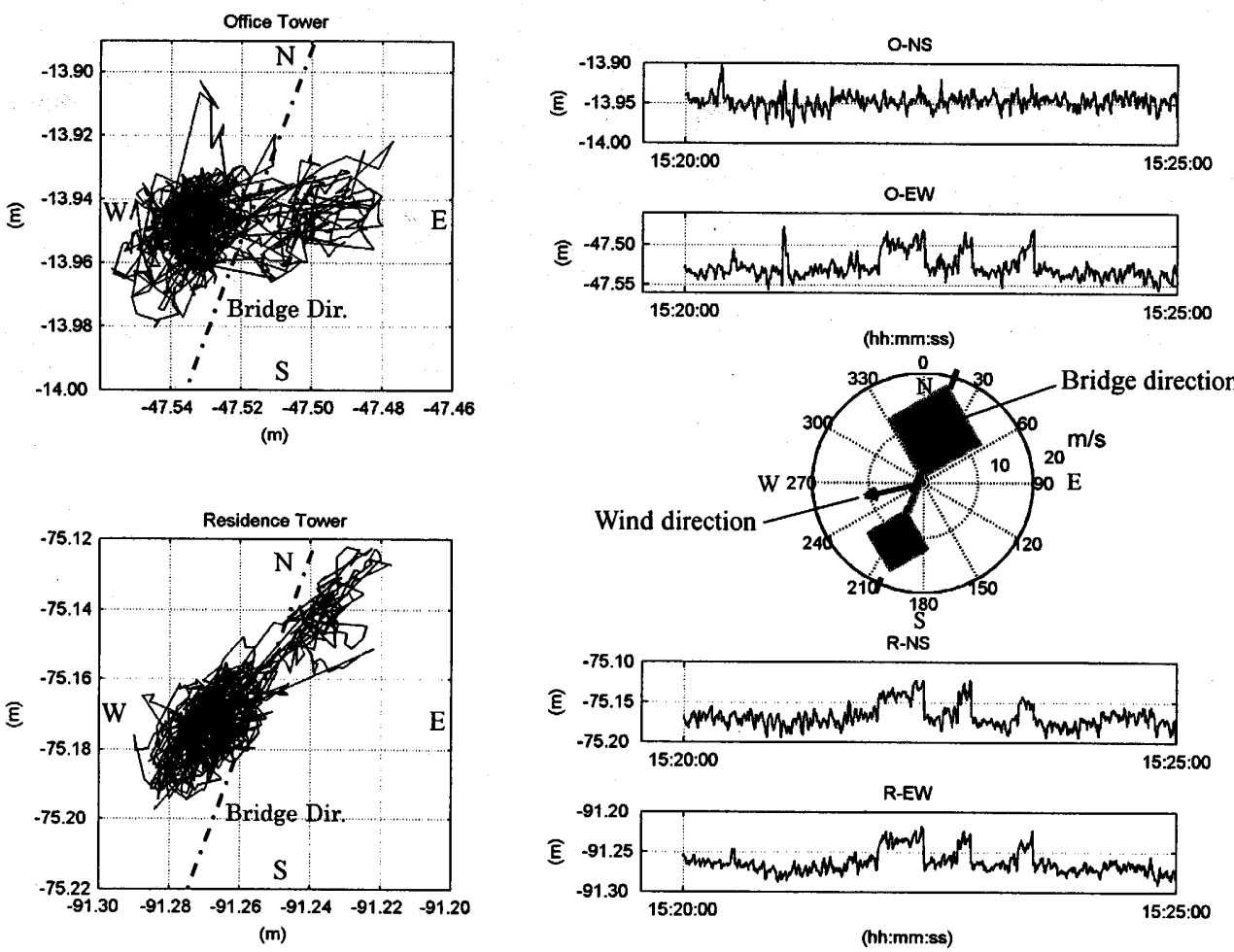

Fig.10 Orbit of the displacement waveforms in OT and RT using GPS and corresponding wind direction.

adjacent high-rise buildings for wind and other external load.

\section{Concluding remarks}

It is shown in this study that the GPS technology can be used for monitoring the high-rise buildings in real-time. First, the applicability of the system is checked using test specimen, which can simulate high-rise buildings. Then, the system is applied simultaneously to two high-rise buildings (Seiroka, St. Luke, twin towers), during a windy day. It is concluded that although the dynamic response of the towers around their fundamental frequency is not well tracked because of low amplitude of dynamic vibration, the long period displacement due to the wind flow is observed. The accuracy of the displacement measurement using GPS remains for further investigation.

\section{Acknowledgment}

The authors are grateful to St.Luke's Towers Co. LTD., for their cooperation during performing the GPS observation.

\section{References}

1- Celebi M.: GPS monitoring of dynamic behavior of long-period structures, Earthquake Spectra, 15, 1, pp. 55-66, 1999.2

2- Tamura $Y$. et al.: Measurement of wind-induced response of building using RTK-GPS, Journal of wind engineering No. 89, pp. 93-96, 2001.

3- GPS Tutorial- Basic of high-precision Global Positioning System, Javad positioning system, 1998

4- Naito Y. and Ishibashi T.: System identification using microtremors of high-rise buildings with close peaks, Annual meeting of AIJ, Paper 21503, pp. 1001-1002, 1996

5- Houghton, E. L. and Carruthers N.B.: Wind forces on buildings and structures, Edward Arnold Ltd, 1976

[2006年 4 月18日原稿受理 2006年 7 月27日採用決定］ 